\title{
Diálogos entre imágenes y sonidos en el imaginario urbano. Ritmando Barcelona(s)
}

\section{Dialogues between images and sounds in the urban imaginary. Barcelona's rhythms}

\author{
Laura Grifol-Isely \\ Université de Franche-Comté, Francia \\ laura.isely@univ-fcomte.fr \\ https://orcid.org/0000-0001-9909-012X
}

\begin{abstract}
Resumen:
Nuestro estudio explora los sonidos de la urbe en su relación con la imagenmovimiento con la intención de observar cómo se ha ido construyendo y deconstruyendo a través del cine contemporáneo un imaginario de la ciudad de Barcelona que, visto en su conjunto, aporta una visión plural, polifónica y heterogénea de la ciudad condal. Apoyándonos en un corpus audiovisual de objetivos, duración, géneros y modo de comunicación extremadamente diverso (compuesto por varios video-clips, un film de ficción, las películas oficiales de los Juegos Olímpicos y varios documentales), trataremos de mostrar que los sonidos a los que se ha ido asociando la urbe, tomados en su conjunto, han jugado un papel fundamental en la configuración de un imaginario complejo de la ciudad, contribuyendo con ello a revelar -igualmente a recrear- su carácter multiversal. En su diálogo con las imágenes, el sonido establece, contradice y refuerza hilos intertextuales entre diversas producciones, dejando huella en una memoria colectiva que contribuye a reinterpretar performativamente.
\end{abstract}

\begin{abstract}
:
Our study explores the sounds of the city in its relationship with the movies in the intention of observing how an imaginary of the city of Barcelona has been built and deconstructed through contemporary cinema. Seen as a whole it provides a plural, polyphonic and heterogeneous vision of Barcelona's city. Relying on an audiovisual corpus of extremely diverse objectives, durations, cinematographic genres and modes of communication such as video-clips, fictional movies, official films of the Olympic Games and several documentaries, we will try to show that the sounds with which the city has been associated, taken as a whole, have played a fundamental role in the configuration of a complex imaginary of the city of Barcelona, thereby contributing to reveal -also to recreate- its multiversal character. In its dialogue with images, sound establishes, contradicts and reinforces intertextual threads between various productions, making a trace in a collective memory that contributes to performative reinterpretation.
\end{abstract}

Palabras clave:

bandas sonoras; cine y ciudad; análisis fílmico; arte contemporáneo; memoria colectiva; Estudios culturales.

\section{Keywords:}

Soundtracks; Cinema and City; Film Analysis; Contemporary Art; Collective Memory; Cultural Studies. 
Le philosophe est libre de voir dans l'« univers du big bang » un cosmos au sens de Démocrite et d'Épicure, hors duquel il n’y a pas « rien », mais une infinité de cosmoi. Selon certains cosmologistes, nous dit-on, « il existe une myriade d'Univers qui se créent en permanence, une infinité vertigineuse d’Univers aux propriétés les plus variées ( Conche, 2005, p. 37)1.

El presente trabajo pretende mostrar que el sonido constituye un elemento fundamental en la configuración de un imaginario heterogéneo y complejo de la urbe. A través del sonido se dice la diversidad, tanto si se considera desde las distintas declinaciones con las que se (re)presenta la ciudad a lo largo del tiempo fílmico de cada película, como a través del poso de memoria que van dejando los sonidos asociados a las imágenes cinematográficas/audiovisuales de una metrópoli. En tanto que ciudad de rodajes, protagonista y tema de numerosas películas, musa de canciones que han lanzado su halo al ámbito internacional, la ciudad de Barcelona ha ido acumulando sonidos que, asociados a una serie de imágenes, le confieren identidad(es) y multiversalidad.

A partir de un corpus voluntariamente heterogéneo ${ }^{2}$ compuesto por una película de ficción, una serie de documentales (distribuidos bien sea por los

1. Traducción propuesta: "Al filósofo le queda la libertad, siguiendo a Demócrito y a Epicuro, de ver en el «universo del big bang» un cosmos fuera del cual no es que no haya «nada», sino más bien una infinidad de cosmoi. Se nos dice que, según ciertos cosmólogos, «existe una miríada de universos en creación constante, una vertiginosa infinidad de universos con las propiedades más variadas»".

2. La elección de un corpus heterogéneo procede de la voluntad de cubrir, a partir de un número escaso de obras, distintas cualidades del objeto de estudio. Del mismo modo que cuando se procede a realizar una secuencia de una película se sitúan varias cámaras en lugares distintos para proceder a dar una visión más completa y compleja de lo que ocurre en escena, del mismo modo que el pintor cubista fragmenta y recompone idealmente su objeto situándose desde distintos puntos de vista, la heterogeneidad del corpus constituye un primer palio dentro del proceso de aproximación al estudio del fenómeno urbano concebido como configuración dinámica compleja. Si por una parte las posibilidades y limitaciones del investigador juegan un papel determinante, los objetivos de la investigación, la perspectiva de la que se parte, el contexto de intelección en el que se realiza, operan de tal modo que no toda elección resulta igualmente pertinente. $\mathrm{Si}$ al principio la intuición guía la mirada, es mediante la exploración atenta como sa van acumulando observaciones que corroboran o desmienten la hipótesis de la que se parte. Se considera que tal o cual obra de un corpus constituido en un principio intuitivamente es o no finalmente pertinente en virtud de la riqueza de interrelaciones que permite descubrir, es decir, en virtud del diálogo que mantiene con los demás elementos del conjunto sin dejar de conservar una idiosincrasia que le es propia. La elección no es ni absolutamente necesaria ni completamente arbitraria, y en ella se conjugan las características propias del objeto con la subjetividad que observa y manipula. En nuestra tesis hemos desarrollado la utilidad de adoptar la "pertinencia" como criterio. En fonología, la pertinencia permite dar cuenta de la diferenciación y la riqueza 
canales de comercialización habituales, bien sea exclusivamente por internet), dos audiovisuales de memoria de espectáculos y de un videoclip, trataremos de mostrar cómo se establece una relación polimorfa entre la imagen y el sonido, personaje(s) y espacio(s), (in)definiciones de género, hibridaciones culturales, melodía armónica y ruido, modernidad y clasicismo, tensión/distensión, recogimiento y empoderamiento, utopía y distopía..., elementos que, vistos en su conjunto, proponen una visión abierta y plural de la ciudad sin excluir focalizar estereotipos, cerrazones y fronteras también presentes en la urbe para con esa misma diversidad.

Con este objetivo, se parte aquí de un marco teórico de vocación transdisciplinar en el que las cualidades relacionantes de nuestro objeto de estudio constituyen el detonante fundamental. Se pretende con ello esbozar una reflexión, con la ayuda de las herramientas propias al análisis del discurso audio-visual (principalmente focalizado en la relación entre ambos componentes), en torno a los distintos aportes sonoros con los que se ha ido configurando un imaginario urbano en el que la ciudad es visualizada como microcosmos pluri-singular. En este sentido, las teorías de la multiversalidad elaboradas desde campos disciplinares distintos, del mismo modo que nociones tales como "ciudades performativas" (Feentra \& Verzero, 2020), a su vez deudoras de los trabajos de Austin (1962) y Searle (1969) sobre los actos de habla, sin olvidar los estudios culturales y los estudios urbanos, así como los aportes de la semiología (Barthes) y el ritmanálisis (Lefebvre \& Regulier) al estudio del ritmo, constituyen los principales pilares teóricos del presente artículo. Transversalidad, performatividad, multi-/pluriversalidad, perspectivismo, pensamiento complejo y lo que Edgar Morin (1995) ha dado

semántica de las palabras a partir de un rasgo distintivo, lo cual remite a la vez a aquel rasgo que la diferencia y a la estrecha relación que mantiene con el resto. Adoptar la pertinencia como criterio permite adaptar la investigación al objeto de estudio atendiendo al proceso y a las distintas etapas entre las que discurre. De manera que un corpus no es nunca pertinente en sí mismo, sino en función de la hipótesis de trabajo y de lo que se va encontrando a medida que se avanza. En el caso de Barcelona, y del espacio urbano en general, nos dimos rápidamente cuenta de que no era suficiente acomodarnos a un único género o tipología audiovisual. La ciudad se resistía a ser monofocalizada. Pertinencia, perspectivismo y work in progress permiten permanecer a la escucha de los lenguajes de la ciudad, de los lenguajes con los que se dice y reinventa la ciudad, de los acordes y discordancias a través de los cuales se nos transmiten diversas percepciones de la metrópoli en tanto que territorio vivido, imaginado, sentido por una multiplicidad de identidades individuales y colectivas. 
en llamar "reliance" (factor relacionante que en nuestra tesis nos condujo a formular la noción de sinapsis sígnicas 3 ), son las principales apuestas metodológicas en las que se apoya este artículo.

Adoptando dicho punto de partida, en primer lugar, trataremos de internarnos en la noción aquí propuesta de multiversalidades urbanas, por parecernos útil para comprender la ciudad contemporánea. Asimismo, nos detendremos brevemente en algunos de los aspectos que encierra el recurso al vocablo 'ritmo' aplicado al estudio de la ciudad y más concretamente al uso que se le confiere en el presente artículo, en el que sólo se accede al espacio urbano a través de sus representaciones audiovisuales que, no olvidemos, incluso en el caso del documental, resultan de una serie de actos de creación. A continuación, propondremos un pequeño recorrido por algunos de los sonidos con los que se ha ido perfilando el imaginario audiovisual de Barcelona, destacando tanto polifonías como etnocaracterizaciones tipológicas, para finalizar centrándonos en las monofonías distendidas con las que ciertos autores de nuestro corpus emprenden una crítica reflexiva sobre las configuraciones distópicas de la urbe.

\section{Multiversalidad(es) urbana(s)}

La noción de multiversalidad procede de la filosofía presocrática. El creciente interés por los fragmentos conservados de/sobre Anaximandro, a quien suele atribuírsele la paternidad de una concepción ilimitada y múltiple del universo, muestra la importancia que reviste en nuestra época la reafirmación de la diversidad, quizá también la necesidad de conciliar

\footnotetext{
3 Dicha noción se relaciona con la lectura o interpretación que resulta del análisis de una película. A través de su película, el cineasta y su equipo, teniendo como interlocutor ideal el público al que se dirigen, nos ofrecen una interpretación, en numerosas ocasiones polisémica, del fenómeno que se escruta con ayuda del ojo-cámara. Apoyándose en el montaje, la imagen-sonido-en-movimiento apunta hacia una serie de relaciones que el contacto cotidiano con los objetos puede mantener velado. Por medio de esta capacidad indicial (deixis), la cámara apunta hacia elementos altamente significativos recorriendo hilos de Ariadna entre conglomerados de sentido (tejido sémico complejo) cuya interrelación puede no resultar evidente a primera vista. De este modo, la cámara puede invitar a recorrer el camino existente entre dos elementos nodales distantes o aparentemente distantes y dotar de significación la relación propuesta sin agotar los significados que idealmente encierra, es decir, las distintas lecturas derivadas, que no se limitan a descifrar un mensaje fijado de una vez por todas, sino que proceden a una re-creación.Véase Grifol-Isely, 2020, pp. 395-396.
} 
diferencia(s), divergencia(s) e intereses comunes. La multiplicación de vertientes teóricas a las que ha dado lugar, de derivados y apropiaciones del vocablo multiverso procedentes de distintos campos disciplinares, dan muestra de la variedad y riqueza de interpretaciones que sugiere. Desde el campo de la astronomía, la filosofía, la sociología, la pedagogía, la literatura o también el cine, el concepto ha ido enriqueciéndose con contenidos de raigambre epistemológica que a su vez sustentan y se sustentan en opciones políticas, económicas, ecológicas y sociales. Algunas de sus vertientes han desembocado en lo que se ha dado en llamar el giro decolonial que, a decir de Walter Mignolo (2007, p. 45), toma raíces en un "pensamiento (...) pluriversal (no universal)" y se muestra a favor de una apertura hacia otros modos de pensar, ver, oír, sentir, nombrar, conocer, transmitir y hacer. A lo que conviene añadir que también ha suscitado arduos debates, prueba quizá de las dificultades de conciliar, tanto a nivel teórico como práctico, lo uno y lo múltiple, o de llevar a la práctica la heterarquía y heteronomía propuestas como fundamento de una concepción pluriversal (Reiter, 2018).

También el arte contemporáneo se ha hecho eco de la complejidad de contenidos que esconden las teorías multiversalistas. Desde la fotografía, se han visto rápidamente las posibles aplicaciones de la noción para pensar, captar y (re)crear la ciudad. En 2012, en el Palau Robert de Barcelona fue organizada una exposición fotográfica bajo el título Barcelona’s Multiverse. Se trataba de una serie de composiciones fotográficas en blanco y negro de Lluis Bussé (2012) en las que el autor ponía en paralelo dos retazos de tomas de lugares emblemáticos de Barcelona creando yuxtaposiciones sorprendentes para los conocedores del lugar, aunque muchas de estas composiciones no resultasen completamente inverosímiles. Con ello se proponía implícitamente, tal es nuestra interpretación, una aplicación de las teorías del multiverso al estudio de la urbe y simultáneamente se apuntaba hacia las raíces urbanas de la teoría de los mundos múltiples. De hecho, en uno de los paneles de la exposición se definía "multiverso" como una "realidad teórica que comprende un número infinito de universos paralelos4".

4La traducción es nuestra. En el original disponible en TV3 (2012) se indicaba lo siguiente:

"Realitat teòrica que comprén un nombre inifinit d'universos paral.lels". 
Por otra parte, la investigación ha puesto en evidencia que tanto en la literatura como en el cine contemporáneos abundan las representaciones de la ciudad como espacio fragmentado a diversos niveles con fronteras más o menos invisibles (Bontemps, Mermier \& Schwerter [dirs], 2018). Con todo, cabe preguntarse en qué medida las disparidades que confluyen en el espacio urbano se mantienen completamente ajenas o si, a pesar de todo, consciente o inconscientemente, interactúan influyendo unas en otras. Planteado dicho interrogante, conviene examinar los sonidos de la urbe para ver si nos permiten encontrar algunas claves de respuesta, no sin antes apuntar hacia una definición de lo urbano como espacio vehículo de tensiones en el que diseminación y retroalimentación (feedback) se dan cita. Así explica David Moriente (2020, p. 236) lo que entiende por ciudad: "sistema de cosmos artificiales estratificados y conectados hiperespacialmente mediante la tensión estructural entre caos y orden (entendidos como conflictos y negociaciones urbanas)". De ahí que pueda resultar particularmente interesante acercarnos al sonido y a los sonidos a través de los cuales nuestros autores han intentado comunicar tensiones y negociaciones, caos y orden, estratificaciones y conexiones, e incluso en ocasiones reinventar la ciudad mediante una refacción/deconstrucción de sus imágenes.

\section{Ritmo, cine y ciudad}

Desde sus comienzos el cine se ha preocupado por sintonizar imagen y sonido, lo cual no es de extrañar si se tiene en cuenta que el llamado "cine mudo" se preocupó desde un principio por aumentar el impacto de las imágenes apoyándose en ruidos y música externas a la cinta. En la actualidad, la banda sonora sigue enfrentándose a la misma dificultad: imagen y sonido deben de alguna manera coincidir y coadyuvar confiriendo un tono o una serie de tonos determinado(s), a su vez motores de un haz de significaciones incompletamente predeterminadas. Imagen $\mathrm{y}$ sonido desconyuntados confieren igualmente una significación al conjunto. Ritmos y arritmias interactúan igualmente en un diálogo interno inevitable por sincronía. 
Ahora bien, la noción de ritmo ha evolucionado a lo largo de la historia. A partir de un estudio de su etimología, Benveniste puso de evidencia que en griego la palabra $\rho v \theta \mu o ́ s$ (ruthmos) tenía un significado más amplio que en la actualidad, y en todo caso principalmente centrado en la idea de 'fluir' presente en la raíz ( $\rho \varepsilon \imath v)$ de la que deriva (1966, p. 327), idea que el sufijo completa aludiendo a la 'modalidad particular que adopta en su cumplimiento'5 (1966, p. 332). Siguiendo su definición de ritmo como "particular modo de fluir", tal y como -según el mismo autor- fue utilizado por los filósofos jónicos para "describir 'disposiciones' o ‘configuraciones' sin fijación ni necesidad natural que resultan de una disposición siempre sujeta a cambio"6 (1966, p. 333), en su segunda lección pronunciada el 12 de enero de 1977 en el Collège de France, Barthes hacía hincapié en el sentido del fluir, de la manera singular con la que los átomos fluyen cambiando de combinaciones, formando constantemente configuraciones cambiantes, por encima del sentido actual de 'mesura' o 'cadencia musical' que el vocablo adopta bajo influencia platónica (29'40" y ss.).

De este modo, Barthes acude al sentido etimológico de la palabra 'ritmo' para desarrollar y dar un esbozo de respuesta en torno a la pregunta que se plantea: ¿Cómo vivir juntos? Y para responder, acude a un neologismo: 'idiorrítmico' e 'ideorritmia', vocablos mediante los cuales apunta hacia una praxis comunitaria que califica de utópica, en la que cada cual, al menos desde la imagen o 'fantasma' del que parte el autor, puede llevar su propio ritmo sin quedar completamente condenado ni a la soledad ni a permanecer sujeto a un ritmo impuesto desde el exterior, un ritmo que, obedeciendo a "una arquitectura de poder" "declarativamente hostil" e "inhumana", obedece a una "forma excesivamente integrativa", estructura conventual propia a la vida en común de tipo monástica en la que cada cuarto de hora queda supeditado a la regla, orden y candencia fijadas, es decir, todo lo contrario del carácter fluyente del ritmo.

5. Traducción propia de: “ modalité particulière de son accomplissement”.

${ }^{6}$. Traducción propia de: “'manière particulière de fluer', (...) décrire des 'dispositions' ou des 'configurations' sans fixité ni nécessité naturelle et résultant d'un arrangement toujours sujet à changer". 
Cabe observar, a partir de este razonamiento, que la palabra ritmo no ha sido únicamente asociada a los orígenes de la materia (atomismo jónico), ni al ritmo musical procedente de una cierta cadencia mesurada (Platón), sino que reviste un contenido ético, y que es posible establecer una relación entre una concepción pluriversal en la que cada universo constituye una figura singular y central, y una concepción idiorrítmica de la convivencia. Paralelamente, la noción de ritmo presentaba tal riqueza de contenidos que, siguiendo a Pinheiro Santos (1931) y a Bachelard (1936), Lefebvre y Régulier (1985) adoptan el neologismo ritmanálisis, adaptándolo al estudio de los ritmos observables en el quehacer cotidiano y en la urbe. Como el urbanista Lynch (1960), tal y como ha puesto de relieve Revol (2019) refiriéndose a una característica que éste mantiene en común con Lefebvre, ambos autores confieren mucha importancia a la "sensibilidad", a la "experiencia estética de los ritmos del entorno urbano".

Añadamos que para Lynch (1960, p. 3) era necesario "considerar (...) la ciudad" a partir de las percepciones de sus habitantes". También introducía la noción de "imágenes colectivas" $(1960$, p. 7) para aludir a percepciones compartidas de las "indicaciones sensoriales" (1960, p. 3) que proporciona el espacio, de entre cuyas propiedades consideraba "el ritmo" (1960, p.10) como uno de los elementos capaces de dejar una imagen fuerte de la ciudad. Por su parte, Lefebvre y Régulier proporcionan una lectura de las ciudades mediterráneas a partir de un análisis de sus ritmos para llegar a la conclusión de que lo que las caracteriza es "la polirritmia" (1986, p.14), lo que les conduce a plantearse una cuestión similar a la planteada por Barthes: "¿Cómo consigue cada cual (individuo-grupo-familia) introducir su propio ritmo entre los de los demás (diferentes), incluso de los impuestos por la autoridad?"9 (1986, p.14).

De todo ello se deduce no sólo que el ritmo es un prisma, incluso una herramienta muy útil para el estudio de la ciudad, de la convivencia y de los

7. En el original: "consider (...) the city being perceived by its inhabitants".

8. Traducción propuesta para la expresión "group images".

9. Traducción propuesta de : « comment chacun (individu-groupe-famille, etc.) parvient-il à insérer ses propres rythmes parmi ceux des autres (différents), y compris les rythmes imposés par l'autorité ? ». 
conflictos geopolíticos que puedan surgir considerando un núcleo urbano desde diferentes escalas (identidades locales, nacionales, relaciones internacionales...), sino que la melodía, la regla, la cadencia, no agota los contenidos que aporta. Ahora bien, podemos preguntarnos en qué medida puede contribuir el estudio de los sonidos audiovisuales que no sólo pretenden captar, comprender, interpretar y transmitir los lenguajes rítmicos de la ciudad, sino incluso reinventar su imagen. A ello intentaremos dar un esbozo de respuesta en los apartados siguientes.

\section{Polifonías urbanas y etnocaracterizaciones tipológicas}

Hacia finales de los ochenta, cuando, a decir de Antonia Casellas, la adjudicación de la celebración de los Juegos Olímpicos había dejado de suscitar un interés unánime (Fills del 92, 17’10”), Barcelona recibía el nombramiento como futura sede del 92. La ciudad aprovechó la oportunidad para capitalizar centralidad y, como se ha dicho en múltiples ocasiones, situarse en el mapa de las ciudades globales. La celebración de los Juegos se vio acompañada de importantes transformaciones urbanas y de una intensa campaña de city branding en la que las declinaciones sonoras de la urbe para renombre de sí misma jugaron un gran papel. Se puede decir incluso que las instituciones locales incentivaron la creación de himnos para la ciudad y que a través de ellos optaron por la configuración de una imagen de marca multicultural, cosmopolita y abierta. A ello contribuyeron igualmente las imágenes, las estrategias y opciones adoptadas para la celebración del evento. Las ceremonias de apertura y de clausura parcialmente recogidas en el Marathon (1993) de Carlos Saura y ampliamente difundidas por los medios de comunicación televisivos dan prueba fehaciente de la importancia que se le concedió a los ítems señalados: 'multiculturalidad' y 'cosmopolitismo' de una 'ciudad abierta'.

La ceremonia del desfile de los participantes lanzó ante el mundo la imagen de atuendos variopintos con los que se procedía a la representación de etnocaracterizaciones tipológicas con las que se pretendía afirmar y reconocer la existencia de singularidades culturales reunidas avanzando 
triunfantes al unísono por las arenas del estadio olímpico al ritmo del Desfile de atletas de Carlos Miranda (Bernat Castillo \& Porta Navarro, 2019, p. 20). La cámara de Saura pone de relieve motivos, colores y formas por medio de planos de detalle y travelings verticales como modos de expresión de la diversidad, dejándose llevar en ocasiones por un cierto voyeurismo que el cineasta se encargó de excusar por medio de un plano subjetivo (sucesivos planos sobre las cámaras y los periodistas, como si la película de Saura no hiciera sino recoger y transmitir material de archivo sin selección previa). Si junto con los atuendos, banderas e insignias representativas de los países participantes concretizaban el mapa geopolítico de antiguos y nuevos conflictos en suspensión o en preparación durante la tregua olímpica, simultáneamente se comunicaba de pasada la capacidad de liderazgo de Barcelona. Con todo, mediante un picado con acentos metacinematográficos (cámaras dentro de campo), la Barcelona olímpica de Saura, aquella misma que como ciudad anfitriona se prestaba al juego de intentar suscitar la admiración, quedaba asimismo supeditada a convertirse en mirador de la sociedad de espectáculo (Debord, 1967).

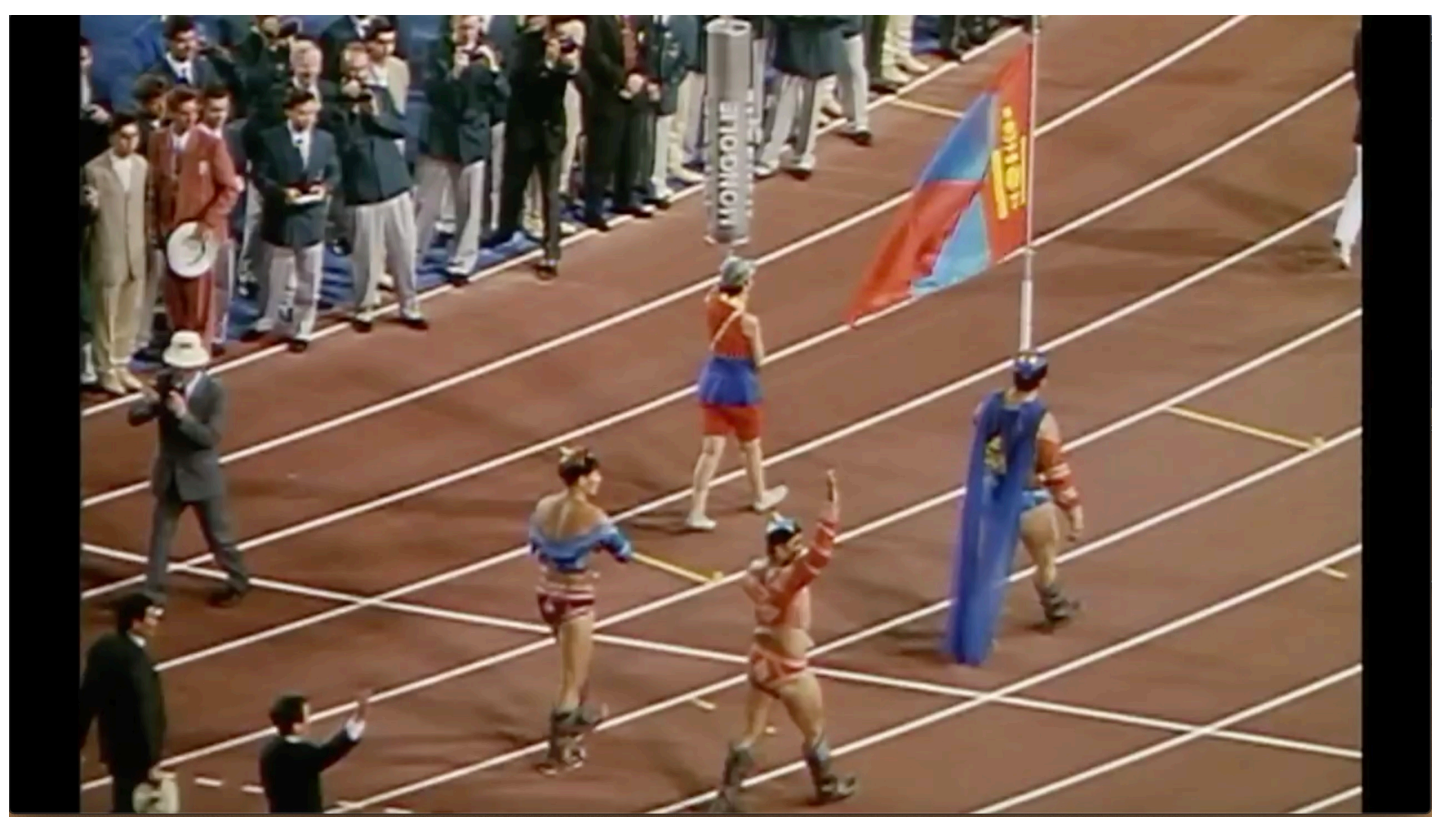

F.1. Marathon, Barcelona, 1992. Fotograma de la Película Oficial de las Olimpiadas, 1993

Afirmándose en su capacidad para entrelazar clasicismo y modernidad a través del espectáculo La Nit (1988) y especialmente de la canción Barcelona 
(Mercury \& Moran, 1987) cantada a dúo por el autor-compositor e intérprete del grupo de rock Queen y la cantante de ópera Montserrat Caballé, la ciudad emitía su novedoso entrelazamiento de sonidos lanzándose al ámbito internacional mientras celebraba el encuentro intergeneracional, el de la cultura de élite y la cultura popular, el de dos lenguas (castellano e inglés) representativas de dos mundos otrora opuestos, en virtud de una armónica simbiosis de hibridaciones culturales. A lo que conviene añadir el himno a Barcelona con el que se cerró la ceremonia de clausura bajo el estribillo "Barcelona tiene poder" (Gitana Hechicera, Pere Calaf/Peret, 1992) llevado por el ritmo festivo de la rumba catalana. Con ello se materializaba en sonidos los sueños de ascensión de una ciudad que se vestía con el imaginario de 'tierra prometida' y se proclamaba como modelo de cuna integración lograda?

Destinado a recoger la memoria de los Juegos, el Marathon de Saura mantiene en su estructura el orden previsto para las ceremonias con la Barcelona de Freddie Mercury al comienzo de la cinta y la de Peret puntuando el final. Ahora bien, conviene indicar que las imágenes que desfilan no guardan relación con los conciertos, lo que confiere mayor sentido a la disociación entre enunciados visuales y enunciados sonoros, ya que la música ni ilustra ni opera como "justificación realista" (Chateau, 1986, p. 147), sino que más bien tiende a introducir un haz de significaciones y a intensificar el impacto emotivo de las imágenes. De hecho, la rumba de Peret acompaña en la película de Saura el espectáculo de globos gigantescos con el que se cerraron los Juegos. Representación de los planetas, mezclando cosmología y mitología, el espectáculo nocturno se convertía en celebración de la pluralidad que conforma el universo, conjugando así lo uno y lo múltiple. En este contexto, Gitana Hechicera ponía fin a la película de Saura acompañando los títulos de crédito y enviaba ante el mundo una serie de ítems, como las raíces interculturales de una ciudad que finalmente se integraba a un cosmos regido por múltiples centralidades, es decir, un cosmos en el que cada unidad actuaba como epicentro de un movimiento conjunto en el que, a imagen y semejanza de la representación interplanetaria, Barcelona interactuaba como parte integrante de fluencias, 
flujos de fuerzas e influencias recíprocas, conjugando sus propios ritmos con los de un orden global.

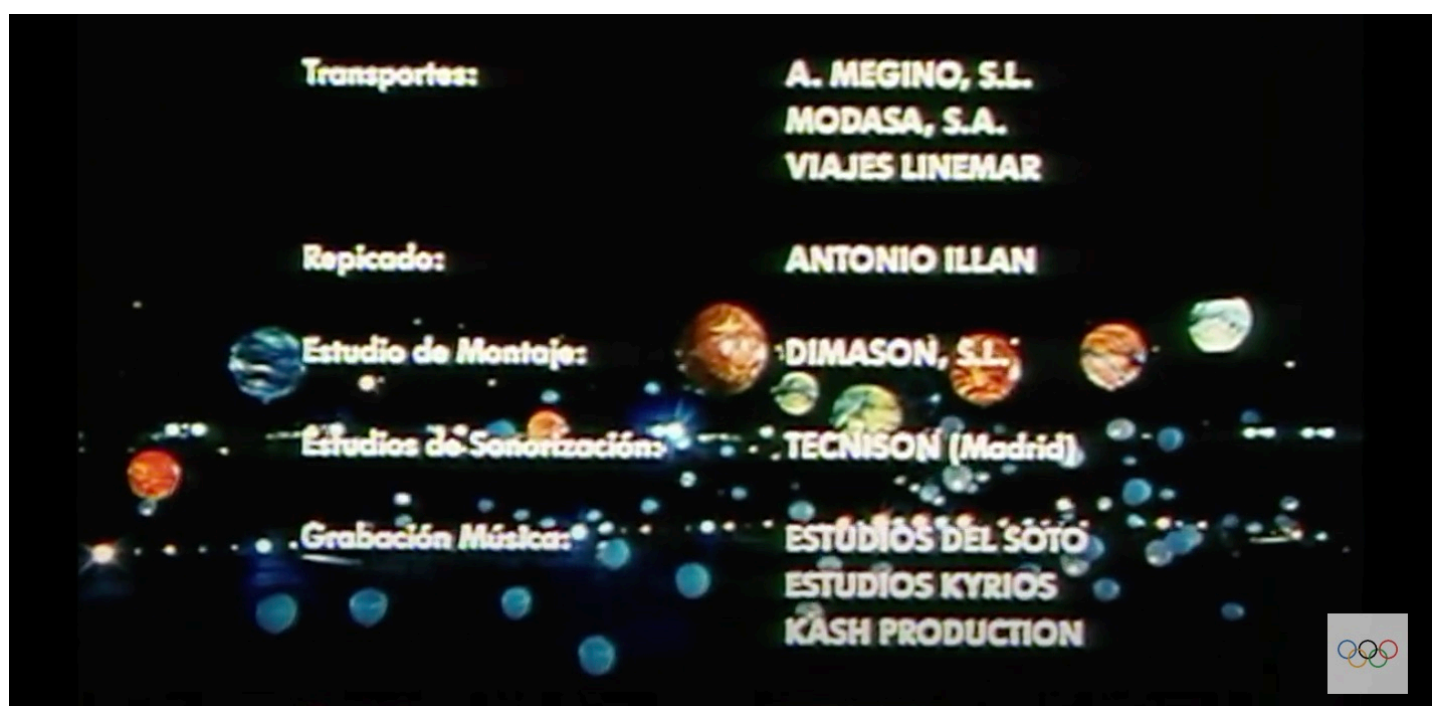

F.2. Marathon, Barcelona, 1992. Fotograma de la Película Oficial de las Olimpiadas, 1993

Canción de apertura y de clausura abren y cierran ese medioparéntesis espaciotemporal con el que el evento irrumpe en lo cotidiano. Pero Saura introduce en el tiempo fílmico sonidos que también recuerdan otro tipo de tensiones que actúan como heridas abiertas en una cotidianeidad que a pesar de todo sigue presente. Memoria del esfuerzo, de los ritos sociales de elevación, del mantenimiento de estructuras de poder y de conflictos más o menos larvados todavía no resueltos, El cant dels ocells, de autor anónimo, introduce simultáneamente un saludo al patrimonio musical de la cultura popular catalana y a la vox populi, estableciendo así aristas de significación polisémicas. Adicionalmente, cabe notar que incluso la comitiva española, en cuyos atuendos se evita hacer hincapié (rojo y amarillo de la bandera española en el vestuario de la comitiva femenina y la corbata de la comitiva masculina), hace su aparición acompañada por los mismos compases que el resto de atletas. Por lo tanto, el énfasis previsto por Carlos Miranda con su pieza España no figura en la Memoria Oficial audiovisual de los Juegos. A lo que conviene añadir que la flagrante diferencia entre la vestimenta de la comitiva femenina (traje de chaqueta y falda de colores vivos hiperbólicamente contrastados) y el traje de la comitiva masculina (pantalones, cromatismo más sobrio) aparece casi silenciada en las imágenes 
de Saura, que sólo deja ver el posicionamiento de ambos grupos: los deportistas delante, las deportistas después.

Este pequeño guiño encuentra ecos más tarde, en el transcurrir del tiempo fílmico, cuando la cámara lenta se detiene (de nuevo hasta el voyeurismo) sobre dos deportistas de lucha libre: el acompañamiento musical acentúa con instrumentos de viento la sensualidad de los luchadores, la ductilidad danzante de movimientos encontrados que, bajo el influjo de las sinuosidades de un acompañamiento musical de acentos orientales, parecen simultáneamente acompasados, celebración de un juego de enlaces y enganches. La música acentúa el efecto de una puesta en cuadro que a su vez pone de relieve las formas corporales, el contacto de los cuerpos, la sensibilidad de ambos contrincantes. Así es como se transgreden y se invita al espectador a ir más allá de los tópicos que se suelen asociar con la lucha libre y la masculinidad.

En 2008, la película de Woody Allen, Vicky Cristina Barcelona, se abre con la canción Barcelona de Giulia y los Tellarini. A ritmo de música ligera, la letra insiste en la imagen de una Barcelona laberíntica -ya presente en la literatura- que contrasta con el ritmo, cuya rapidez queda acentuada por el uso de instrumentos de cuerda y una cadencia acelerada. De este modo se inscribe inmediatamente el laberinto en el registro del juego, e incluso en el del juego infantil, dado el desenfado con el que la voz narrativa invita a recorrerlo. Igualmente, se establecen vínculos intertextuales con Gitana Hechicera de Peret al finalizar con el estribillo "Barcelona es poderosa", que en algunas versiones llega incluso a formularse mediante una cita explícita, cuando el coro de fondo, a ritmo de rumba, repite "Barcelona tiene poder" hasta dejar la canción en suspenso.

A propósito de ello, es interesante observar cómo se va estableciendo un diálogo interno entre los sonidos y semas con los que se va revistiendo la urbe. Las relaciones intertextuales (citas, alusión y referencias comunes) observables entre los documentos de nuestro corpus revelan que cada uno de ellos viene a tomar parte desde un punto de vista distinto en un debate colectivo en el que se reactualizan, interpretan o refutan sonidos y ritmos de un pasado más o menos reciente. Así, por ejemplo, el poema Oda a 
Barcelona (Maragall, 1909) muy probablemente inspirador del adjetivo "hechicera" de la rumba de Peret, se transforma en canción de rap para poner fin al documental de Mireia Ros Antes de que el tiempo lo borre (2010). Precisamente, la Barcelona que nos invitan a recorrer las imágenes mezclando lugares emblemáticos como La Pedrera o la torre Abgar con tiendas multiprecio de productos importados, invita a cuestionar la supuesta identidad de la urbe al mismo tiempo que el documental la rebusca entre sus escrituras arquitectónicas y las acciones de aquellos que se implicaron para imprimirle un sello. Tradición (poema de J. Maragall) y modernidad (rap) se combinan para intentar re-presentar el ánima presupuesta de una urbe en la que la figura del palimpsesto convive con la del mosaico. El documental de Ros rebusca entre pasado y presente la llama de una ciudad que mueve y es movida, una ciudad dínamo que se retroalimenta con la actividad de sus gentes, esa misma actividad a la que les incita. No obstante, también se encuentra con una ciudad cercada, que sitúa más bien en el presente, atada de pies y manos frente a una globalización galopante que enajena a sus gentes de un espacio cuyas transformaciones y nuevas escrituras se materializan sin su aporte en una coyuntura que despoja de las posibilidades económicas para continuar la labor iniciada por aquellos que vieron en la ciudad y su marca patrimonial una marca de su propio prestigio.

Así, la cineasta nos invita a observar algunas de las complejidades de los mecanismos de (des)memorialización (Feenstra \& Verzero, 2020) que intervienen en el presente, pues las generaciones actuales no disponen de medios adecuados para asegurar el relevo. Sirviéndose de procedimientos propios del cine de los orígenes, deudor asimismo de los artilugios del espectáculo de magia, la cineasta recurre a la superposición de dos rodajes: de fondo, en una puesta en abismo que ocupa la totalidad del cuadro, una película en la que se propone un recorrido por la ciudad. En primer término, un personaje imitando el acto de deambular. De este modo se hace patente la fractura existente entre el personaje, en primer término, y la ciudad escenario (segundo término) por la que circula cotidianamente, adoptando bastante alegremente un ritmo acelerado que desde la ciudad mastodonte (el 
segundo término ocupa la mayor parte del cuadro) y los valores contemporáneos se le impone y se autoimpone.

Amputados de las escrituras de su pasado, desfiguradas éstas bajo un disfraz de feria, los habitantes inscriben sus vidas al margen de una biografía urbana cuya savia aparece como congelada (cortes sucesivos con elipsis de buena parte del recorrido para destacar una serie de monumentos que parecen posar literalmente para una cámara en pequeños travelings encadenados). Mientras, las imágenes desfilan a ritmo de rap para ilustrar una oda (Maragall, 1909) en la que la ciudad, pasado y presente entrelazados por una relación dialógica, se (re)afirma como una ciudad-mosaico, discordante y diversa, personificada y capaz de suscitar emociones (enumeración de adjetivos calificativos con polisíndeton, gradación ascendente, apropiación por medio del posesivo, reduplicación, hipérbole y exclamativos: "vana i coquina i traïdora i grollera/(...) Barcelona! (...)/ Barcelona nostra! La gran encisera!".

En contraste, ofreciendo una vista sobre la epidermis de la ciudad, Alberto Castaño y Luis Caldevilla nos ofrecen una Barcelona onírica por medio de una sinfonía urbana. El acompañamiento musical, única voz para una "ciudad-cuerpo" (Verzero, 2020, p. 96) de matices cambiantes, amplifica el impacto de las imágenes acentuando los efectos claramente impresionistas con los que el tiempo recorre, horizontal y verticalmente, sinuosidades geométricas y cavidades interiores para internarse en la Sagrada Familia y ofrecérnosla desde distintos prismas. Desde la ciudad imaginada, se nos interna en lo sacro inmanente dejando que la música, a modo de trovador, nos cuente sus historias, elevando a la categoría de protagonista el monumento emblemático, sinécdoque de Barcelona.

Figura inacabada, figura en proceso de construcción, figura personificada habitada por su propio ritmo, pero también inmersa en una marea urbana en la que fluyen otros ritmos, aquellos en los que estridencias y cacofonías forman parte habitual de una ciudad atmosféricamente proclive a la celebración del evento. Entre lo sagrado y lo profano, acompañando el viaje interior con música de Bach (Misa en si menor), Stefan Haupt invita a recorrer luces y formas desde el interior del citado templo, limitando la voz 
en off a lo mínimo para reproducir por unos instantes un efecto intimista exploratorio. Pero si lo hace, es también para acentuar el contraste con los ruidos de la calle que de pronto irrumpen en la banda sonora, como en la música concreta, mientras la cámara lanza, por medio de un plano general, una mirada hacia las multitudes noctámbulas de una ciudad animada. Al ritmo de pitos y flautas (hinchas celebrando la victoria), la ciudad festiva se expresa por medio de lenguajes urbanos fácilmente reconocibles de identidades globales y locales.

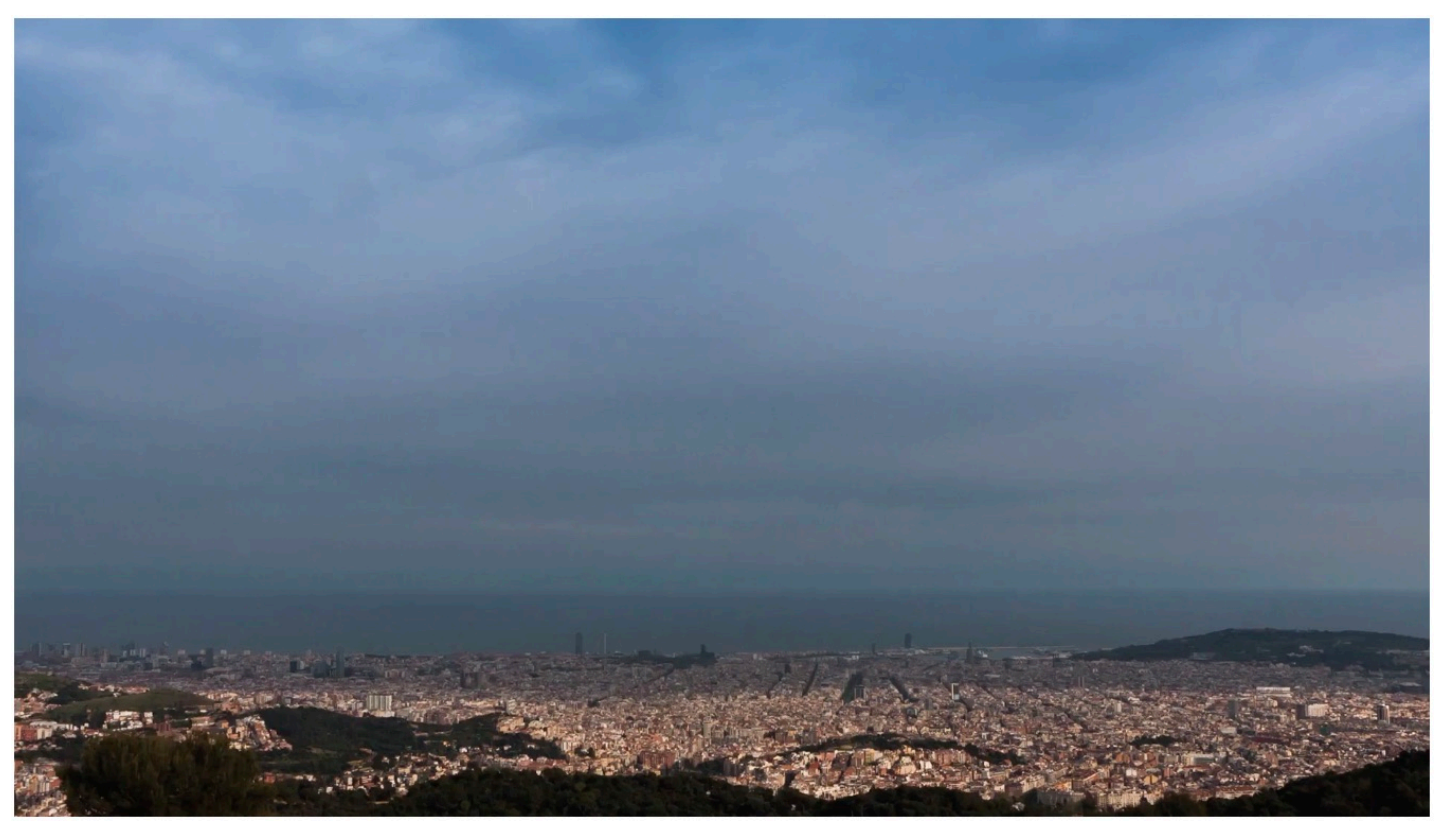

F.3. Sagrada Familia, Barcelona, 2012-2013. Fotograma audiovisual Castaño \& Caldevilla

Cabe observar pues que a través del sonido se establecen vasos comunicantes con los que distintos autores de distinta procedencia e incluso épocas van dejando una huella en la "memoria colectiva" (Halbwachs, 1950) hecha de refacciones/reactivaciones sucesivas que pueden coincidir o no en algunos de los ítems de los que se ha ido revistiendo su imaginario de ciudad agente, ciudad personaje y protagonista.

La noción de "ciudades performativas" puede ser muy útil para comprender dicho fenómeno. Pietsie Feenstra y Lorena Verzero (2020, p. 14) la definen del siguiente modo:

La noción de ciudades performativas, tal como la pensamos, propone una perspectiva de análisis que pone el foco en el carácter performativo del espacio 
urbano; es decir, en la capacidad de "hacer algo" de las prácticas que en él se realizan.

A partir de ahí nos atrevemos a sostener que el sonido, en su diálogo con las imágenes, participa en la creación de unas prácticas artísticas que confieren a la ciudad la facultad de co-performar. Es decir, como indican las mismas autoras, la capacidad "de colaborar en la transformación de las subjetividades, en la percepción del mundo y las prácticas colectivas” (2020, p. 13). En el apartado siguiente intentaremos exponer algunos ejemplos que permiten observar que el sonido también colabora en el ejercicio de la función crítica: apoyándose en algunos procedimientos sonoros, los cineastas participan en un debate público e incitan a participar en él aportando argumentos y un impacto sensorial emotivo.

\section{El espacio urbano y sus monofonías distendidas}

Hacia finales del siglo XX se produce un giro en las políticas culturales europeas que incentivan las acciones que tienen como objetivo la configuración de lo que se ha dado en llamar ciudades creativas. En definitiva, se trataba de paliar los efectos de la desindustrialización por medio de la creación de una imagen atractiva de la ciudad tomando anclaje en la creación artística, dotada de alto valor simbólico. Simultáneamente, el arte adoptaba una función social y política en la (re)constitución de la convivencia, mientras el cine proseguía su marcha ambivalente, concebido a la vez como pilar de arranque de una imagen de marca ciudad, industria cultural, inversión comercial, factor de cohesión social y como herramienta indicial para señalar e invitar a reflexionar sobre los problemas que aquejan a las sociedades contemporáneas.

Concebida como microcosmos de una serie de configuraciones que se imponían con fuerza en la era de lo que Henri Lefebvre denominó La revolución urbana (1970), la ciudad será tomada por las autoridades locales, en ocasiones expresamente, como laboratorio de prueba. Buena parte de las transformaciones urbanas serán planeadas apoyándose en una política cultural multidimensional que irá desde la creación de centros de difusión y encuentro hasta la ampliación de la red de casas culturales y bibliotecas, e 
incluso la transformación de antiguos espacios fabriles en centros culturales o de antiguas cárceles de mujeres y hospitales de obras de beneficencia en museos y lugares destinados al estudio, proyección, promoción del cine e intercambios culturales (conocimiento de otros cines).

El resultado, quizá también uno de los incentivos liminares, una serie de proyectos arquitectónicos de pequeña, mediana y gran envergadura con los que la ciudad se disponía a entrar de pleno en la modernidad y emprendía un proceso de borrado selectivo de parte de sus memorias. Junto a las Film Commission, destinadas en principio a atraer un remanente de rodajes extranjeros, aparecen nuevos centros de creación artística, se destina el Palau de la Virreina a cumplir con la función de centro expositivo de la imagen, se promueven festivales, premios y ayudas a la creación artística y acogida de artistas, se aumenta la oferta formativa del audiovisual pública y privada, profesional y universitaria (lo cual revierte en un mundillo de jóvenes dispuestos a hacer su entrada en el estudio, las prácticas profesionales, la creación audiovisual y la interpretación), se crea un centro para la conservación de la imagen en las cercanías de Barcelona (Terrassa) y se construye un edificio en el centro de la ciudad para albergar la Filmoteca. Se sigue pues, a nivel del audiovisual, un modelo de negocio, político y cultural plural, aunque no necesariamente horizontal, que ha aportado para la ciudad una imagen polifacética en la que se incluye, en la tónica del poema de Maragall, la autocrítica, apuntando hacia la construcción de un imaginario de ciudad creativo-reflexiva, a la vez nudo de tensiones y vigía.

En este sentido, buena parte de creaciones audiovisuales documentales barcelonesas de las primeras décadas del siglo XXI, adoptan desde un principio una misión comunicativo-performativa atenta a las dificultades de ejercicio de la casi recién estrenada democracia. Muchas de ellas se hacen eco y se convierten en canal y escritura de performances colectivas. Sin tener necesariamente origen en prácticas artísticas, dichas performances colectivas encuentran en las prácticas artísticas audiovisuales modos de expresión, visibilidad y legitimación. Buena parte de estas creaciones han encontrado canal de comunicación en los medios que las nuevas tecnologías han puesto a su alcance, pero también constituyen un indicio de las condiciones en las que 
emergen, alimentadas por el contexto crono-territorial. Es decir, que encuentran en la ciudad una atmósfera adecuada para la (re)creación de sinergías. Sin hacer la unanimidad, los participantes en las manifestaciones ciudadanas escribían con sus cuerpos y voces la existencia de percepciones compartidas que (re)activaban por medio de los rituales de recorrido y ocupación masiva de un lugar o zona(s) urbana(s).

Como ejemplo, destaquemos el audiovisual Bye, bye Barcelona de Eduardo Chibás (2014). De origen venezolano y residente en Barcelona, formado a la historia del arte y al montaje, realizó integralmente un documental rápidamente compartido por internet. En él, el autor se hacía eco de las manifestaciones ciudadanas contra la turistificación masiva de algunos barrios emblemáticos de la ciudad. Una de las estrategias estilísticas de mayor impacto en el documental consiste en la creación de lo que denominaremos crono-cartografías del suspense.

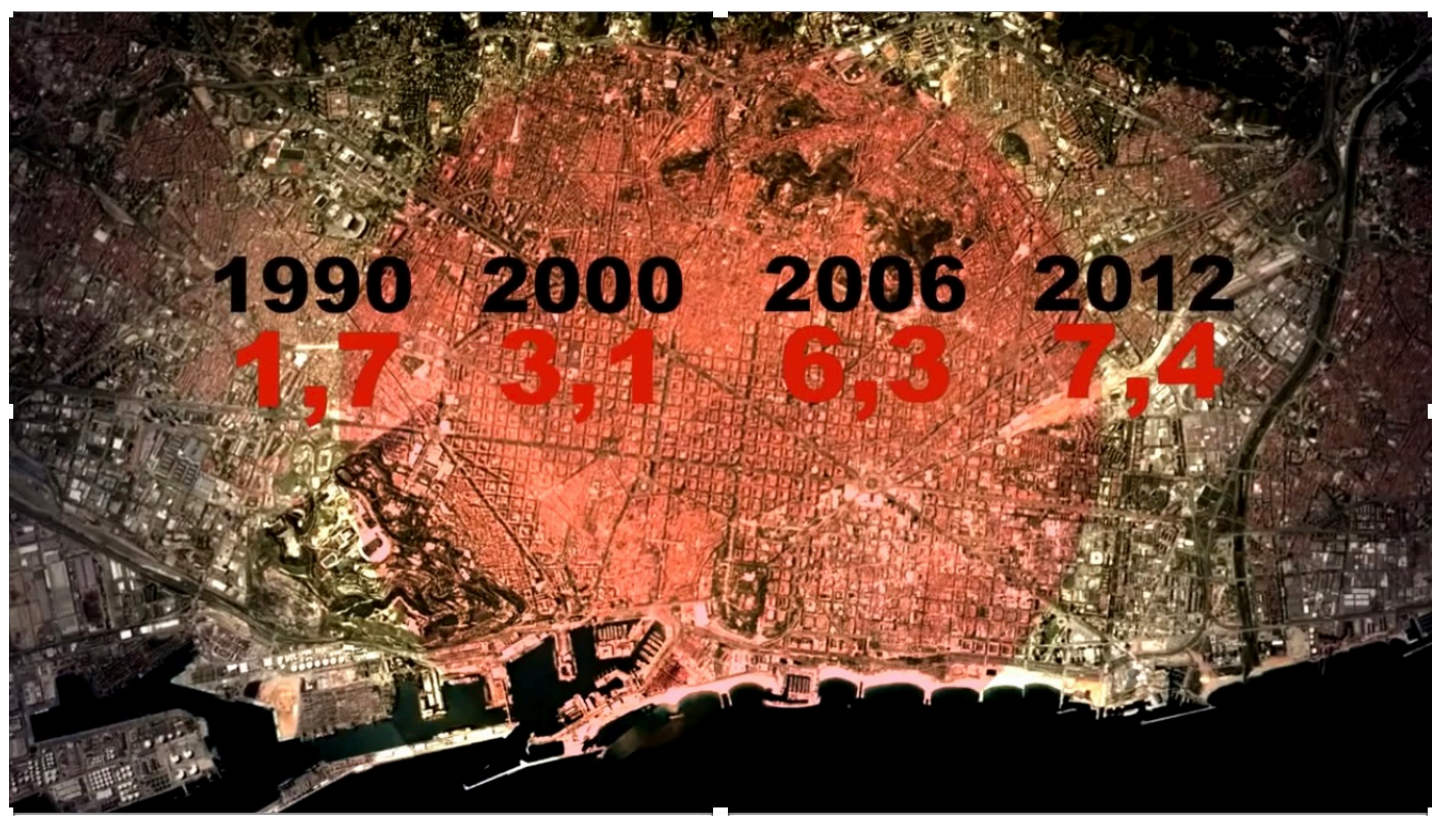

F.4. Bye bye Barcelona, Barcelona, 2014. Fotograma audiovisual de Chibás.

En efecto, valiéndose de las técnicas del suspense in crescendo tan habituales en las películas de terror, se van superponiendo una serie de pastillas circulares en rojo de dimensiones cada vez mayores sobre un mapa de la ciudad, mientras van apareciendo sobre el mapa porcentajes indicativos del crecimiento exponencial de turistas entre finales del siglo $\mathrm{XX}$ y principios del 
XXI. A medida que la mancha roja se va expandiendo sobre el mapa, un fondo musical acompasado fundiéndose en prolongaciones agudas y una serie de ruidos acrecientan el sentimiento de angustia que provoca el tic-tac acelerado de un cronómetro mientras las campanadas de la Sagrada Familia y el bullicio de la calle se apoderan de la banda sonora dejada en suspensión hasta la aparición de un cartón negro con el que se anuncia el paso a las entrevistas.

Estridencias y sonidos agudos alargándose en un tempo indefinido hasta la suspensión son los mismos con los que en Ciutat morta (Artigas \& Ortega) se alude a heteronomías de género que, por medio de una puesta en abismo de una performance teatral, se intenta deconstruir. Imprimiendo insultos en la escayola que cubre el cuerpo de las performers, se revierte el significado de los agravios que por ende se convierten en lenguaje de la disidencia, reescritura y (re)memorialización de las representaciones y normas que dictaminan comportamientos en función de identificaciones genéricas tipificadas. Paralelamente, es a través de los ruidos de la calle y un sonido agudo distendido como la cámara al hombro de Ciutat morta acompaña, en primeros planos dorsales y medios laterales, a una multitud singularizada por la importancia que se le concede a la parte superior del cuerpo, permitiendo incluso el acceso a algunos rostros. Sonidos de empoderamiento y desobediencia civil (altavoz, ruidos de aforo), subrayan el acto de okupación de una sala de cine para la proyección de la película.

Parecido recurso fónico fue utilizado por el equipo Sub (T. Badía, O. Comeron, J.L. Marzo, M. Romaní \& G. Trujillano) en su documental MACBA, la derecha, la izquierda y los ricos (2013). A medida que la imagen va emergiendo sobre un fondo blanco que permanece como filtro entre fotografía referente (representantes conocidos de la vida política, económica y cultural de la ciudad y el país) e imagen en movimiento mientras un lento travelling atrae la atención sobre los personajes implicados en el proyecto de dar a la ciudad un museo de arte contemporáneo, se intensifica delicadamente un fondo sonoro lento y distendido (Esti dal, Kodaly) con el que se refuerza el sentido dé́ctico de una imagen destinada a (re)memorializar la memoria colectiva. A modo de puntos suspensivos, las 
notas prolongadamente distendidas de un murmullo coral invitan a una suspensión del juicio y a una reflexión crítica de las narrativas triunfalistas con las que autoridades y actores culturales del momento acogieron y promovieron el proyecto. Entretanto, a través de una serie de carteles fijos impresos sobre la imagen fotográfica, el documental asume un papel deconstructor de los argumentos en los que dichas narrativas se apoyaban, yendo más allá de la simple información. A ello contribuye el filtro nebuloso de la imagen audiovisual, pues a través de ella se elabora un discurso metacinematográfico polifónico con el que se nos invita a adentrarnos en los múltiples significados que encierra el arte y la política de las transparencias. Mediovelada por el filtro, la fotografía invita a observar las opacidades blancas que se esconden tras los acuerdos institucionales destinados a dotar a la ciudad de un museo de arte contemporáneo.

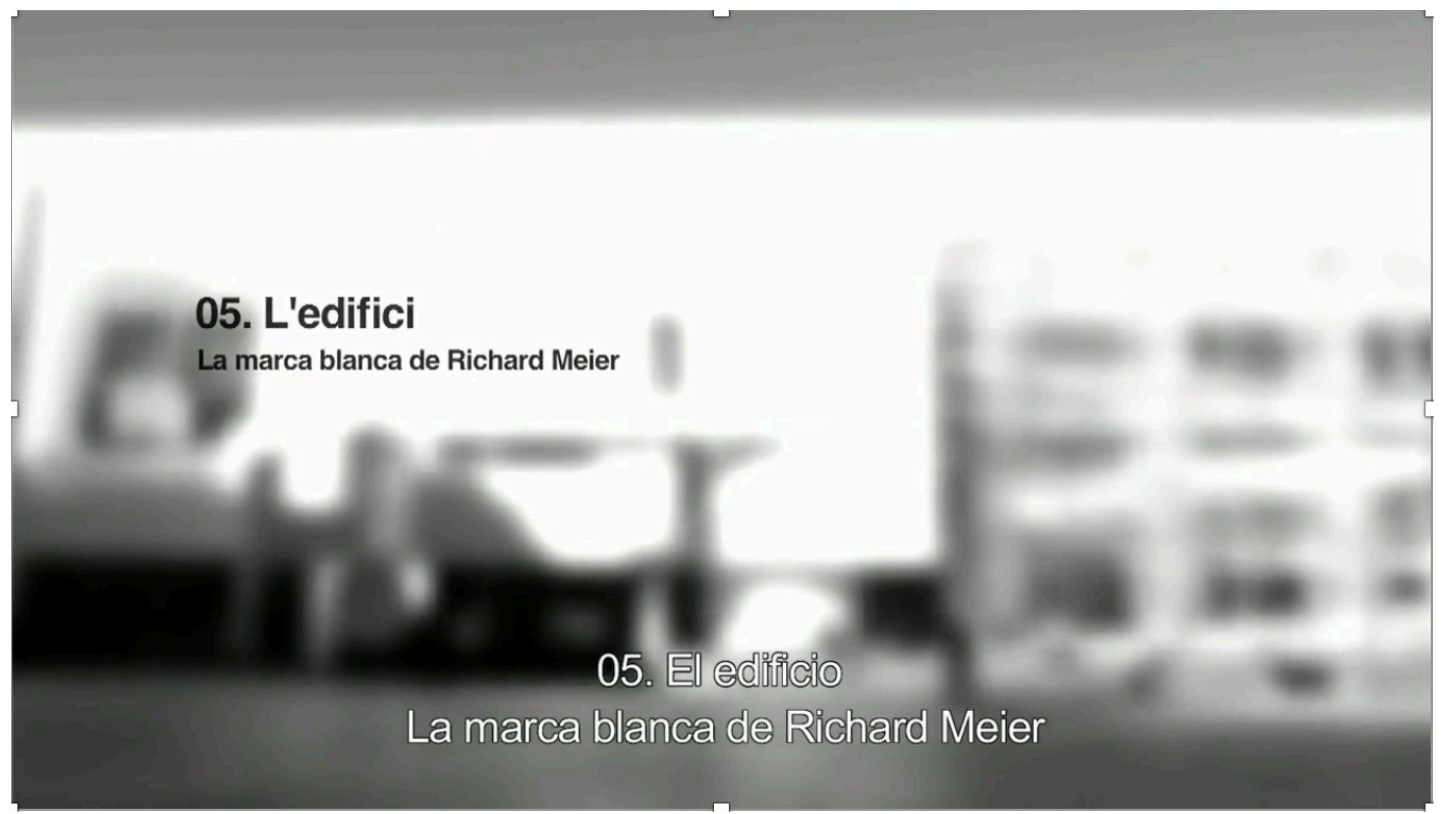

F.5. MACBA, la derecha, la izquierda y los ricos, Barcelona, 2013. Fotograma audiovisual Equipo Sub

Con ayuda del mismo recurso, imagen fotográfica velada por la sobreexposición de una blancura dominante de entre la que va emergiendo una imagen cada vez más nítida antes de volver a difuminarse bajo el velo, el documental va puntuando los diez capítulos de los que se compone, a modo de decálogo. Cada capítulo ofrece una toma o varias del edificio blanco de Richard Meier. Pero de Kodaly, se pasa a utilizar un fragmento de la canción 
Llévame al museo, papi (Trujillano, 2006) como base deíctico-sonora de las puntuaciones que estructuran el documental, estableciendo así nudos mnemotécnicos con un video-clip viral con el que Trujillano parodiaba, a ritmo de flamenco-pop-reggaeton, tanto los tópicos del españolismo como los de la música comercial y el sexismo, para culminar con una crítica abierta al cultivo de una cultura de élite a la que no adhiere el público, mientras otras expresiones culturales más populares carecen de medios de difusión institucionales. Entretanto, se deja filtrar intertextualmente un fragmento de la canción de la Barcelona de Mercury que se ha convertido viralmente en símbolo del triunfalismo expositivo de los noventa, invirtiendo con ello la 'narrativa del éxito' que coadyuvó a generar.

Para concluir, a partir de todo lo dicho, cabe inferir el gran potencial mnemotécnico de la banda sonora. Contribuyendo a la integración de asociaciones de imágenes y sonidos en la memoria colectiva, los distintos matices tonales con los que se va declinando la urbe confluyen en la creación de un imaginario ciudad con múltiples significados y efectos. Tejiendo relaciones intertextuales con sonidos diacrónica y diametralmente distanciados, sin dejar de nutrir una relación emotivo-afectiva, contribuyen a escribir las textualidades con las que se expresa y se miente la ciudad, para co(n)formar conjuntamente una memoria heterogénea del imaginario y el architexto urbano (autor/a, 2020, p. 420). De este modo, Barcelona, la ciudad-mosaico que ha adoptado el trencadís como imagen de marca, también encuentra entre la imagen y el sonido intersticios de memorias de fracturas, memorias de emergencias.

\section{Referencias bibliográficas}

Austin, J.L. (1962). How to do Things with words. Oxford: Oxford University Press.

Chateau, D. (1986). Le cinéma comme langage. Paris: Publications de la Sorbonne.

Bachelard, G. (1936). La Dialectique de la durée. Paris: Boivin \& Cie. 
Barthes, R. (1977). "Comment vivre ensemble? - Sur l'idiorrythmie. Cours au Collège de France”, enero- mayo. En Rhuthmos, 22 de julio 2021 [en línea], https://rhuthmos.eu/spip.php?

Benveniste, E. (1966). Problèmes de linguistique générale, 1. Paris: Gallimard.

Bernat Castillo, M. \& Porta Navarro, A. (2019). "La música de los Juegos Olímpicos de Barcelona. Estudio de la ceremonia inaugural y aproximación didáctica". Castellón: Universitat Jaume I. URI: http://hdl.handle.net/10234/183187. Consulta el 11/10/2021.

Bernd, R. (ed.) (2018). Constructing the Pluriverse. The Geopolitics of Knowledge. Durham \& London: Duke University Press.

Bontemps, V., Mermier, F. \& Schwerter, S. (dirs.) (2018). Les villes divisées. Récits littéraires et cinématographiques. Villeneuve d'Asq: Presses universitaires de Septentrion.

Bussé, Ll. (2012). Barcelona’s Multiverse. Bolonia: Damiani.

Conche, M. (2005). Philosopher à l’infini. Paris: PUF (Presses Universitaires de France), Col. Perspectives Critiques.

Debord, G. (1967). La société du spectacle. Paris: Buchet-Chastel.

Feenstra, P. \& Verzero, L. (2020). Ciudades performativas: prácticas artísticas y políticas de (des)memoria en Buenos Aires, Berlín y Madrid. Buenos Aires: Universidad de Buenos Aires \& Instituto de Investigaciones Gino Germani, Col. CLACSO.

Grifol-Isely, L. (2020). Barcelona en pantalla: dinámicas conjuntas de realización de una biografía urbana. Estudio comparativo centrado en la evolución de las representaciones cinematográficas de la ciudad condal en la encrucijada de los siglos XX y XXI (1992-2017). [Tesis dirigida por N. Berthier (Sorbonne-Université) y V. Sánchez-Biosca (Universitat de València)].

Halbwachs, M. (1950). La mémoire collective. Paris: Les Presses universitaires de France (1967).

Lefebvre, H. (1970). La révolution urbaine. Paris: Gallimard.

Lefebvre, H. \& Regulier, C. (1985). "Le projet rythmanalytique". En Communications, $\mathrm{n}^{\circ}$ 41, pp. 191-199.

Lefebvre, H. \& Regulier, C. (1986). "Essai de rythmanalyse des villes méditérranéennes”. En Peuples Méditerranéens, ${ }^{\circ}$ 37, oct.-dic. 1986, pp. 5-16.

Lynch, K. (1960). The Image of the City. Massachusetts: The M.I.T. Press.

Maragall, Joan (1909). Oda nova a Barcelona. Barcelona: Ayuntamiento de Barcelona, 1960. Disponible en http://www.bcn.cat/museuhistoriaciutat/verdaguermaragall/o2.html.

Mignolo, W. (2007). "El pensamiento decolonial: desprendimiento y apertura”. En S. Castro- Gómez \& R. Grosfoguel (eds.). El giro 
decolonial. Reflexiones para una diversidad epistémica más allá del capitalismo global, (pp. 25-46). Bogotá: Siglo del Hombre Editores; Universidad Central, Instituto de Estudios Sociales Contemporáneos y Pontificia Universidad Javeriana, Instituto Pensar.

Moriente, D. (2020). "Conflictos visuales en la representación de la ciudad : paisajes artificiales de la memoria”. En Pietsie, F. \& Verzero, L. (2020). Ciudades performativas: prácticas artísticas y políticas de (des)memoria en Buenos Aires, Berlín y Madrid, (pp. 235-250) Buenos Aires: Universidad de Buenos Aires \& Instituto de Investigaciones Gino Germani, Col. CLACSO.

Morin, E. (1995). "La stratégie de la reliance pour l'intelligence de la complexité". En Revue Internationale de Systémique, vol. 9, $\mathrm{n}^{\circ} 2$.

Revol, C. (2019). "Kevin Lynch et Henri Lefebvre, penseurs de l'expérience esthétique des rythmes de l'environnement urbain". En Rhuthmos, 21 de octubre [En línea]. Disponible en https://rhuthmos.eu/spip.php?article852.

Searle, J. R. (1969). Speech Acts. Cambridge: Cambridge University Press.

Verzero, L. (2020).“Teatralidad, memoria y experiencia en la ciudad-cuerpo: practices performáticas en la Buenos Aires del siglo XXI”. En Pietsie, F. \& Verzero, L. (2020). Ciudades performativas: prácticas artísticas y políticas de (des)memoria en Buenos Aires, Berlín y Madrid, (pp. 93106) Buenos Aires: Universidad de Buenos Aires \& Instituto de Investigaciones Gino Germani, Col. CLACSO.

\section{Filmografía y audiovisuales}

Allen, W. (2008). Vicky Cristina Barcelona. 1 DVD. Warner video.

Anglarill, E. \& Arranz, M. (2017), Fills del 92. TVE, La 2:

https://www.rtve.es/rtve/20170725/tve-catalunya-estrena-fills-del-92documental-commemora-els-25-anys-dels-jocs-olimpicsbarcelona/1586842.shtml

Artigas, X. \& Ortega, X. (2013). Ciutat Morta. Disponible en https://www.youtube.com/watch?v=8zng8Nlof2U.

Castaño, A. \& Caldevilla, L. (2012-2013). Sagrada Familia. Disponible en http://emeshing.blogspot.com/2013/o6/timelapse-sagrada-familia-bycapdevila.html.

Chibás, E. (2014). Bye bye Barcelona. Disponible en https://www.youtube.com/watch?v=kdXcFChRpmI.

Equipo Sub (2013). MACBA, la dreta, l'esquerra i els rics/ MACBA, la derecha, la izquierda y los ricos. Disponible en https://www.youtube.com/watch?v=rDzt22T-xJY.

Haupt, S. (2012), Sagrada: El misterio de la creación. 1DVD. Suiza: Fontana Film.

Mercury, F. \& Caballé, M. (1988). Barcelona (Live at 'La Nit', Remastered). Disponible en https://www.youtube.com/watch?v=hkskujGoUYc. 
Peret (1992). Gitana Hechicera. En "Ceremonia de clausura. Barcelona 1992”. Disponible en https://olympics.com/es/video/barcelona-1992ceremonia-de-clausura.

Ros, M. (2011). Abans que el temps ho esborri/Antes de que el tiempo lo borre. 1DVD: Cameo.

Saura, C. (1993). Marathon. Película Oficial de los Juegos Olímpicos.1DVD: Iberoamericana Films Producción.

Trujillano, G. (2006). Llévame al museo, papi. Video-clip. Disponible en https://www.youtube.com/watch?v=aV-7G-3ZOSs.

TV3 a la carta. (10/o8/2012). Barcelona's Multiverse. Última consulta el $10 / 10 / 2021$ en https://www.ccma.cat/tv3/alacarta/programa/barcelonasmultiverse/video/4199290/. 